\title{
Partial Privatization in Upstream Mixed Oligopoly with Free Entry
}

\author{
Chu-Chuan Hsu \\ Department of Marketing and Logistics Management, YuDa University of Science and Technology, Taiwan \\ Email: edison9@ydu.edu.tw
}

How to cite this paper: Hsu, C.-C. (2016)

Partial Privatization in Upstream Mixed Oligopoly with Free Entry. Modern Economy, 7, 1444-1454.

http://dx.doi.org/10.4236/me.2016.712132

Received: October 10, 2016

Accepted: November 7, 2016

Published: November 10, 2016

Copyright $\odot 2016$ by author and Scientific Research Publishing Inc. This work is licensed under the Creative Commons Attribution International License (CC BY 4.0).

http://creativecommons.org/licenses/by/4.0/ (c) (i) Open Access

\begin{abstract}
Utilizing the model with upstream mixed oligopoly in which there are one public and $n$ private wholesalers in the upstream market, and $m$ private retailers in the downstream market, this paper examines the optimal privatization policy of the upstream public wholesaler. It shows that: Firstly, in an environment with mixed oligopoly in the wholesale market and many private firms in the retail market, the public wholesaler should be partially privatized in the short run. Besides, the more private firms are in wholesalers or retailers market, the higher degree of privatization the government should take. Secondly, the public wholesaler should be partially privatized in the long run; moreover, the more private retailers firms are in the market, the less degree of privatization the government should take. Thirdly, the difference of optimal degree of privatization between long run and short run is increasing in the market scale and decreasing in the entry cost. Hence, the optimal degree of privatization in long run is smaller than in short run, when the market scale is restricted and the entry cost is high.
\end{abstract}

\section{Keywords}

Upstream Mixed Oligopoly, Free Entry, Privatization

\section{Introduction}

Recently, a growing amount of literature on the privatization issue in mixed oligopoly has been seen. Regarding the policy of partial privatization ${ }^{1}$, Matsumura [1] in mixed duopoly explicitly considered the possibility of partial privatization, and showed that neither full privatization nor full nationalization is optimal. In a closed-market homogeneous oligopoly, Matsumura and Kanda [2] demonstrated that partial privatization is ${ }^{1}$ In fact, recently the consideration of partial privatization is applied to various issues in mixed oligopoly. See, for example, Jiang [6] on wage bargaining, Bárcena-Ruiz and Garzón [7] and Méndez-Naya [8] on merger, Heywood and Ye [9] on delegation etc. 
the optimal policy in the short-run; full nationalization is always optimal in the long run with free entry among private firms. Brandão and Castro [3] extended the framework by Matsumura and Kanda [4], and demonstrated that the presence of a public enterprise can be an alternative to direct regulation to avoid the excess entry problem. Fujiwara [4] developed a differentiated mixed oligopoly model to establish what implication product differentiation has for the optimal privatization policy and showed that the short-run-optimal policy is non-monotonic in the degree of love of variety, while the optimal degree of privatization is monotonically increasing in the consumer's preference for variety in the long run.

Wang and Chen [5] envisage three scenarios, which are one benchmark regarding an autarky market and two open-market counterparts, to explore the influences of cost efficiency gain and foreign competitors on equilibrium outcomes. In contrast to the case in Matsumura and Kanda [2], critical cost gap determines that long-run degree of privatization is larger than the short-run one. In particular, regarding the scenario wherein one public firm competes with domestic private firms and foreign private firms, equilibrium price is lower than marginal cost of public firm instead of being equivalent to marginal cost of the public firm. They find that public firm's outputs, profit, and social welfare are the largest in the autarky scenario; contrarily, public firm's outputs, profit, and social welfare are the smallest in mixed oligopoly wherein one public firm competes with domestic private firms and foreign private firms.

While Matsumura and Kanda [2] and Wang and Chen [5] show an important limitation of the "optimal privatization policy at the free entry market" and provide important policy implications, they have ignored an important market structure, viz., the input of the final goods. Hence, a more comprehensive treatment incorporating the input pricing activities of the intermediate goods producers and the final goods producers deserve attention in examining privatization policy of entry in a vertical structure. We take up this issue in this paper and derive the following findings: Firstly, in an environment with mixed oligopoly in the wholesale market and many private firms in the retail market, the public wholesaler should be partially privatized in the short run. Besides, the more private firms are in wholesalers or retailers market, the higher degree of privatization the government should take. Secondly, the public wholesaler should be partially privatized in the long run; moreover, the more private retailers firms are in the market, the less degree of privatization the government should take. Thirdly, the difference of optimal degree of privatization between long run and short run is increasing in the market scale and decreasing in the entry cost. Hence, the optimal degree of privatization in long run is smaller than in short run, when the market scale is restricted and the entry cost is high.

The remainder of this paper is organized as follows. We present the basic model in Section 2. Major results are derived and explained in Sections 3 and 4. The final section is the concluding remarks.

\section{The Basic Model}

We assume that in a mixed oligopoly structure, there are one partially state-owned 
wholesaler and $n$ private wholesalers in the upstream, while there are $m$ private retailers in the downstream. All the upstream wholesalers, no matter whether it is the public or the private ones, sell homogeneous intermediate goods. It requires one unit of intermediate goods for producing one unit of final goods. Both the upstream and the downstream markets are engaging in Cournot competition. The market demand is characterized by a linear function $p=a-Q$, where $a$ denotes the market scale, $p$ stands for the market price. $Q=q_{0}+\sum_{i=1}^{n} q_{i}=\sum_{j=1}^{m} q_{j}$ is the total market output, where $q_{0}$, $q_{i}$ and $q_{j}$ are respectively, the sale amount of the public wholesaler, the private wholesalers and private retailers. We assume that both public and private wholesalers have the same increasing marginal cost function ${ }^{2}$; namely, $C\left(q_{l}\right)=\left(q_{l}^{2} / 2\right)+f^{2}$, $l=0, i$, where $f^{2}$ stands for the fixed cost. The only cost that private retailers entail is the wholesale price $w$ determined by the wholesaler, excluding the fixed or variable costs, say the warehouse or transportation costs. Moreover, we also assume that the objective of this public firm, before privatization, is to maximize the social welfare. To launch the privatization policy, the government, adopting the equity offering, restructures the public firm into a mixed enterprise, and shares the ownership with private investors.

The profit functions of the public wholesaler, the private wholesalers, and the private retailers are as follows respectively:

$$
\begin{gathered}
\pi_{0}=w q_{0}-\frac{1}{2} q_{0}^{2}-f^{2} \\
\pi_{i}=w q_{i}-\frac{1}{2} q_{i}^{2}-f^{2}, i=1, \cdots, n \\
\pi_{j}=(p-w) q_{j}, \quad j=1, \cdots, m,
\end{gathered}
$$

where $S W$ denotes the social welfare, and $C S=Q^{2} / 2$ is the consumer surplus. The social welfare function is the summation of consumer surplus and the profits of all the public and the private firms. Accordingly, the social welfare function is

$$
S W=C S+\pi_{0}+\sum_{i=1}^{n} \pi_{i}+\sum_{j=1}^{m} \pi_{j} .
$$

The objective function of the public firm is the weighted average of both its profit and social welfare. Thus, we express its objective function as

$$
V=\lambda \pi_{0}+(1-\lambda) S W .
$$

where $\lambda$ is the weight on producer profits in the decision-making process of the firm, namely degree of privatization, and $0 \leq \lambda \leq 1$. Following Matsumura [1], we assume that the government can indirectly control $\lambda$ through its shareholding. The fully private firm maximizes its profit if $\lambda=1$; contrarily, a fully state-owned firm maximizes the social welfare if $\lambda=0$.

In the following, a three-stage game is used to explore how the government determines the optimal privatization policy. At Stage 1, by maximizing the social welfare, the government determines the optimal degree of privatization; at Stage 2, it is the Cournot

${ }^{2}$ De Fraja and Delbono [10] assume that both the public firm and the private firm have increasing marginal cost functions. With this assumption, it is not the optimum policy for a public firm to supply all the market demand. 
competition where the public firm, given the privatization degree, determines the optimum wholesale amount and competes with other private wholesalers; at Stage 3, the private retailers are in Cournot competition as well. As usual, this game is solved by subgame perfection deduced through backward induction.

\section{Optimal Privatization Policy at Regulated Entry}

We start by considering Stage 3. Retailers are in Cournot competition to determine the optimal retail quantity $\left(q_{j}^{*}\right)$. Since the objective of the retailer is profit maximizing, we partially differentiate the retailer's profit function with respect to $q_{j}$ which yield the first order condition:

$$
\frac{\partial \pi_{j}}{\partial q_{j}}=-2 q_{j}+a-w-\sum_{h=1}^{m-1} q_{h}=0, \quad j=1, \cdots, m, h \neq j .
$$

We then get the equilibrium retail price $q_{j}^{*}$ :

$$
q_{j}^{*}=\frac{a-w}{m+1}, j=1, \cdots, m .
$$

From Equation (5), we obtain the retailer's profit, the wholesale price and the aggregate profit of the wholesale market respectively in the following expression:

$$
\begin{gathered}
\pi_{j}=\left(\frac{a-w}{m+1}\right)^{2}, j=1, \cdots, m \\
w=a-\frac{m+1}{m} Q \\
\sum_{j=1}^{m} \pi_{j}=m\left(\frac{a-w}{m+1}\right)^{2}=\frac{Q^{2}}{m} .
\end{gathered}
$$

Then, in Stage 2, we find the optimal wholesale output for the wholesalers. By substituting the preceding solutions into Equation (1), the profit functions of the public wholesaler and the private firm are rewritten as follows:

$$
\begin{gathered}
\pi_{0}=\left(a-\frac{m+1}{m} Q\right) q_{0}-\frac{q_{0}^{2}}{2}-f^{2} \\
\pi_{i}=\left(a-\frac{m+1}{m} Q\right) q_{i}-\frac{q_{i}^{2}}{2}-f^{2}, i=1, \cdots, n .
\end{gathered}
$$

The first-order conditions of the above maximization problems are

$$
\begin{aligned}
& \frac{\partial V}{\partial q_{0}}=a-\frac{3 m+2}{m} q_{0}-\frac{m+1}{m} \sum_{i=1}^{n} q_{i}+(1-\lambda)\left[\frac{m+2}{m} q_{0}+\frac{1}{m} \sum_{i=1}^{n} q_{i}\right]=0 \\
& \frac{\partial \pi_{i}}{\partial q_{i}}=a-\frac{m+1}{m} q_{0}-\left[q_{i}+\frac{m+1}{m}\left(2 q_{i}+\sum_{k=1}^{n-1} q_{k}\right)\right]=0, i=1, \cdots, n, k \neq i .
\end{aligned}
$$

The wholesale market is in homogeneous goods competition, we express $\sum_{k=1}^{n-1} q_{k}$ as $(n-1) q_{i}$. From these two preceding equations, we can obtain the optimal output levels for the public wholesaler and the private ones as follows: 


$$
\begin{gathered}
q_{0}=\frac{a m(2 m+1+n-n \lambda)}{m[2+n+m(4+n)]+\{2+n+m[5+2 n+m(2+n)]\} \lambda} \\
q_{i}=\frac{a m[m-1+(2+m) \lambda]}{m[2+n+m(4+n)]+\{2+n+m[5+2 n+m(2+n)]\} \lambda}, i=1, \cdots, n .
\end{gathered}
$$

The equilibrium input price is

$$
w^{*}=\frac{a(2 m+1)[\lambda(m+2)+m-1]}{m[m(n+4)+n+2]+\lambda\{m[m(n+2)+2 n+5]+n+2\}} .
$$

From comparative static analysis, we obtain that:

$$
\begin{gathered}
\frac{\partial w}{\partial m}=\frac{a\left\{2+n-\lambda-n(1-\lambda) \lambda+2 m[4+n+(n-2) \lambda]+m^{2}[8-4 \lambda+n(3-\lambda)(1+\lambda)]\right\}}{(m[m(n+4)+n+2]+\lambda\{m[m(n+2)+2 n+5]+n+2\})^{2}}>0 \\
\frac{\partial w}{\partial n}=\frac{a(m+1)(2 m+1)(m+\lambda+m \lambda)[m-1+(m+2) \lambda]}{(m[m(n+4)+n+2]+\lambda\{m[m(n+2)+2 n+5]+n+2\})^{2}}<0 \\
\frac{\partial w}{\partial \lambda}=\frac{a(m+1)(2 m+1)^{2}(m+n+2)}{(m[m(n+4)+n+2]+\lambda\{m[m(n+2)+2 n+5]+n+2\})^{2}}>0 .
\end{gathered}
$$

In the short run, the equilibrium input price of intermediate good will increase because the increase of the derive demand which is called the "pass through effect"; when the number of the firm in the wholesaler market increases, the equilibrium input price of intermediate goodwill decrease because the market is soften; the higher degree of the privatization will push up the equilibrium input price of intermediate good is because the decrease in the production of the public firm will decrease the supply of the intermediate goods.

Substituting $q_{0}$ and $q_{i}$ into other equations, we get equilibrium aggregate market output, equilibrium market price, consumer price, and profit functions of the public wholesaler and the private one as follows:

$$
\begin{gathered}
Q=\frac{a m[1+n \lambda+m(2+n+n \lambda)]}{m[2+n+m(4+n)]+\{2+n+m[5+2 n+m(2+n)]\} \lambda} \\
p=\frac{a m(1+2 m+n)+a[2+n+m(5+2 m+n)] \lambda}{m[2+n+m(4+n)]+\{2+n+m[5+2 n+m(2+n)]\} \lambda} \\
C S=\frac{a^{2} m^{2}[1+n \lambda+m(2+n+n \lambda)]^{2}}{2\{m[2+n+m(4+n)]+\{2+n+m[5+2 n+m(2+n)]\} \lambda\}^{2}} \\
\pi_{0}=\frac{a^{2} m(1+2 m+n-n \lambda)\{-2+4 \lambda+m[2 m-n-3+(10+4 m+n) \lambda]\}}{2\{m[2+n+m(4+n)]+\{2+n+m[5+2 n+m(2+n)]\} \lambda\}^{2}}-f^{2} \\
2\{m[2+n+m(4+n)]+\{2+n+m[5+2 n+m(2+n)]\} \lambda\}^{2}-f^{2}, i=1, \cdots, n
\end{gathered}
$$




$$
\pi_{j}=\frac{a^{2}[1+n \lambda+m(2+n+n \lambda)]^{2}}{\{m[2+n+m(4+n)]+\{2+n+m[5+2 n+m(2+n)]\} \lambda\}^{2}}, j=1, \cdots, m .
$$

From Equations (8) and (9), we find that the output of the public wholesaler outnumbers that of the private wholesaler. Similar to the results obtained in other studies without concerning vertical market structure, our finding also indicates that the public firm will produce more for the consideration of social welfare.

Moreover, by using the foregoing equations, we can derive the impact of privatization degree $\lambda$ on the individual firm's output, market aggregate output, market price, and consumer surplus as follows:

$$
\begin{gathered}
\frac{\partial q_{0}}{\partial \lambda}=-\frac{a m(1+2 m)(2+n+m)[1+n+m(2+n)]}{\{m[2+n+m(4+n)]+\{2+n+m[5+2 n+m(2+n)]\} \lambda\}^{2}}<0 \\
\frac{\partial q_{i}}{\partial \lambda}=\frac{a m(1+m)(1+2 m)(2+n+m)}{\{m[2+n+m(4+n)]+\{2+n+m[5+2 n+m(2+n)]\} \lambda\}^{2}}>0 \\
\frac{\partial q_{j}}{\partial \lambda}=-\frac{a m(1+2 m)^{2}(2+n+m)}{\{m[2+n+m(4+n)]+\{2+n+m[5+2 n+m(2+n)]\} \lambda\}^{2}}<0 \\
\frac{\partial Q}{\partial \lambda}=-\frac{a m(1+2 m)^{2}(2+n+m)}{\{m[2+n+m(4+n)]+\{2+n+m[5+2 n+m(2+n)]\} \lambda\}^{2}}<0 \\
\frac{\partial p}{\partial \lambda}=\frac{a m(1+2 m)^{2}(2+n+m)}{\{m[2+n+m(4+n)]+\{2+n+m[5+2 n+m(2+n)]\} \lambda\}^{2}}>0 \\
\frac{\partial C S}{\partial \lambda}=-\frac{a^{2} m^{2}(1+2 m)^{2}(2+n+m)[1+n \lambda+m(2+n+n \lambda)]}{\{m[2+n+m(4+n)]+\{2+n+m[5+2 n+m(2+n)]\} \lambda\}^{3}}<0 .
\end{gathered}
$$

From the above equations, we see that as the degree of privatization increases, the output of the public wholesaler shrinks, while that of the private wholesaler expands and that of private retailer decreases. The aggregate market output goes down and that will boost up the market price. Hence, consumer surplus declines.

Finally, we go to the first stage, and solve the government's social welfare maximization problem to get the optimal degree of privatization. From the first order condition for social welfare maximization with respect to $\lambda^{3}$ :

$$
\frac{\partial S W}{\partial \lambda}=\frac{a^{2} m(1+2 m)(2+n+m)^{2}\{m(1+m)[n(1-\lambda)-4 \lambda]-\lambda\}}{\{m[2+n+m(4+n)]+\{2+n+m[5+2 n+m(2+n)]\} \lambda\}^{3}}=0 .
$$

We obtain the optimal degree of privatization $\lambda^{*}$ in the short run:

$$
\lambda^{*}=\frac{m(1+m) n}{1+m(1+m)(4+n)} .
$$

${ }^{3}$ The second order condition $\partial^{2} S W / \partial \lambda^{2}<0$ is assumed. 
When $0<\lambda^{*}<1$, it implies that with the objective of social welfare maximization, the optimal privatization policy for the public firm is neither sole public ownership nor sole private ownership, but a partially private one. From the analysis above, we can conclude the following proposition.

Proposition 1: In an environment with mixed oligopoly in the wholesale market and many firms in the retail market, the public wholesaler should be partially privatized in the short run.

Besides, from Equation (14), we perceive how the number of private wholesalers or that of private retailers affects the optimal degree of privatization. It shows that:

$$
\begin{aligned}
\frac{\partial \lambda^{*}}{\partial n} & =\frac{m(1+m)(1+2 m)^{2}}{[1+m(1+m)(4+n)]^{2}}>0 \\
\frac{\partial \lambda^{*}}{\partial m} & =\frac{n+2 n m}{[1+m(1+m)(4+n)]^{2}}>0 .
\end{aligned}
$$

The optimal degree of privatization for the public firm depends on the number of private wholesalers or that of private retailers. When the number of private firms increases in wholesalers and retailers market, the government should increase the optimal degree of privatization.

\section{Optimal Privatization Policy with Free Entry of Upstream Firms}

In the long run, the government may liberalize the market with free entry ${ }^{4}$ which leads to zero profit for all the private wholesalers. Substituting Equation (8) and Equation (9) into $\pi_{i}=0$ yields the following constraint:

$$
\pi_{i}^{*}=\frac{a^{2} m^{2}(2+3 m)[m+(2+m) \lambda-1]^{2}}{2\{m[2+n+m(4+n)]+\{2+n+m[5+2 n+m(2+n)]\} \lambda\}^{2}}-f^{2}=0 .
$$

From Equation (17), we derive the number of the private wholesalers under free entry:

$$
n^{E}\left(\pi_{i}=0\right)=n(\lambda, a, f, m) \text { and } n^{E}=\frac{\sqrt{2} a \sqrt{m(2+3 m)}\{[m+(2+m) \lambda-1]-2 f(1+2 m)[2 \lambda+m(2+\lambda)]\}}{2 f(1+m)(m+\lambda+m \lambda)} \text {. }
$$

From Equation (18), we find that the impact of the optimal privatization degree or private retailer number on the optimal number of private wholesaler in the free entry upstream market. We express them respectively in the following equations:

$$
\frac{\partial n^{E}}{\partial \lambda}=-\frac{(1+2 m)\left(\sqrt{2} a \sqrt{m(2+3 m)}+2 f m^{2}\right)}{2 f(1+m)(m+\lambda+m \lambda)^{2}}>0
$$

\footnotetext{
${ }^{4}$ The government may liberalize the retailer market with free entry. However, since we assume retailers entail no fixed cost, the individual retailer still enjoys positive profit even in the long run with free entry. Thus, there is no optimal number of the retailer firms.
} 


$$
\frac{\partial n^{E}}{\partial m}=\frac{\sqrt{2} a\left[m+5 m \lambda^{2}+m^{3}(5-\lambda)(1+\lambda)+2 m^{2}(1+\lambda)(2+\lambda)+\lambda(2 \lambda-1)\right]-2 f \sqrt{m(2+3 m)}\left\{\lambda^{2}+4 m \lambda+m^{2}[2+(3-\lambda) \lambda]\right\}}{2 f \sqrt{m(2+3 m)}(1+m)^{2}(m+\lambda+m \lambda)^{2}}>0 \cdot(20
$$

From Equation (19), we also perceive that with free entry in the upstream market, the optimal private wholesaler number $\left(n^{E}\right)$ existing in the market is in positive correlation with both the optimal privatization degree $(\lambda)$ and private retailer number $(m)$. This implication is that when the optimal privatization degree or the number of private retailers increases, the number of private wholesalers in the market will raise up.

Substituting Equation (18) into Equations (5), (8) and (9), we get the outputs of the public firm and the private firms and wholesale price in the following expression:

$$
\begin{gathered}
q_{0}^{E}=\frac{m[\sqrt{2} \sqrt{m(2+3 m)} a(1-\lambda)+2 f(1+2 m)(m+\lambda)]}{\sqrt{2} \sqrt{m(2+3 m)}(1+m)(m+\lambda+m \lambda)} \\
q_{i}^{E}=\frac{f m}{\sqrt{m+\frac{3 m^{2}}{2}}} \\
q_{j}^{E}=\frac{\sqrt{2} \sqrt{m(2+3 m)} a-2 f(1+2 m)}{\sqrt{2} \sqrt{m(2+3 m)}(1+m)} \\
w^{E}=\frac{f(1+2 m)}{\sqrt{m+\frac{3 m^{2}}{2}}}
\end{gathered}
$$

From comparative static analysis, we obtain that:

$$
\frac{\partial w}{\partial m}=-\frac{\sqrt{2} f(1+2 m)}{(m(2+3 m))^{3 / 2}}<0
$$

In the long run, the equilibrium input price of intermediate good will decrease rather than increase is due to the deterrence effect of entry cost that will make the number of the firm in the downstream market becomes smaller and consequently, decreases the derive demand. The long run effect of firm entry in downstream market on the equilibrium input price of intermediate good is different from the short run "pass through" effect.

Furthermore, we find that:

$$
\begin{gathered}
\frac{\partial q_{0}^{E}}{\partial \lambda}=-\frac{m(1+2 m)\left(\sqrt{2} \sqrt{m(2+3 m)} a+2 f m^{2}\right)}{\sqrt{2} \sqrt{m(2+3 m)}(1+m)(m+\lambda+m \lambda)^{2}}<0 \\
\frac{\partial q_{i}^{E}}{\partial \lambda}=\frac{\partial q_{j}^{E}}{\partial \lambda}=\frac{\partial w^{E}}{\partial \lambda}=0 .
\end{gathered}
$$

From the results of Equations (25) and (26), we find that, in the industry environment with free entry, the government's optimal privatization policy will only affect the optimum wholesaler number in the market or the output of the public firm. Neither the

${ }^{5}$ Some relevant studies, please see Matsumura and Kanda [2] and Fujiwara [4] etc. 
output of any individual private firm nor the optimum wholesale price is affected ${ }^{5}$.

Then, we go back to the first stage. In an industry environment with free entry, we solve the government's social welfare maximization problem with respect to the optimal privatization degree. Substituting Equation (18) to Equation (2) gives us the long run social welfare level. From the first order condition, we get the long run optimal privatization degree as follows ${ }^{6}$ :

$$
\lambda^{E}=\frac{m\left\{a^{2} m(2+3 m)+\sqrt{2} a f \sqrt{m(2+3 m)}[m(m-2)-1]-2 f^{2} m^{2}(1+2 m)\right\}}{a^{2} m^{2}(2+3 m)+\sqrt{2} a f \sqrt{m(2+3 m)}\left[1+3 m\left(1+m+m^{2}\right)\right]+2 f^{2} m^{2}(1+2 m)\left(1+m+m^{2}\right)}<1
$$

From Equation (27), we perceive the impact of the private retailer number, the market scale and the entry cost on the long run optimal privatization degree as follows ${ }^{7}$ :

$$
\begin{aligned}
\frac{\partial \lambda^{E}}{\partial m}= & \frac{-f m(1+m)}{\sqrt{m(2+3 m)}\left\{a^{2} m^{2}(2+3 m)+\sqrt{2} a f \sqrt{m(2+3 m)}\left[1+3 m\left(1+m+m^{2}\right)\right]+2 f^{2} m^{2}(1+2 m)\left(1+m+m^{2}\right)\right\}^{2}} \\
& \times\left\{\sqrt{2} a^{3} f m(2+3 m)\left(6 m^{3}-7 m-3\right)+2 a^{2} f \sqrt{m(2+3 m)}\left(2+9 m+3 m^{2}-22 m^{3}-12 m^{4}+12 m^{5}\right)\right. \\
& \left.+2 \sqrt{2} a f^{2} m^{2}\left(4+18 m+15 m^{2}-23 m^{3}-24 m^{4}+m^{5}\right)+4 f^{3} m^{3}\left(1+3 m-4 m^{3}\right) \sqrt{m(2+3 m)}\right\}<0 \\
& \frac{\partial \lambda^{E}}{\partial a}=\frac{f m^{2}(1+m)^{2}\left\{(1+2 m) \sqrt{2 m(2+3 m)}\left[2 f^{2} m^{3}+a^{2}(2+3 m)\right]+4 a f m^{2}[2+m(7+6 m)]\right\}}{\left\{a f \sqrt{2 m(2+3 m)}\left[1+3 m\left(1+m+m^{2}\right)\right]+m^{2}\left[a^{2}(2+3 m)+2 f^{2}(1+2 m)\left(1+m+m^{2}\right)\right]\right\}^{2}}>0 \\
& \frac{\partial \lambda^{E}}{\partial f}=\frac{a m^{2}(1+m)^{2}\left\{-(1+2 m) \sqrt{2 m(2+3 m)}\left[2 f^{2} m^{3}+a^{2}(2+3 m)\right]-4 a f m^{2}[2+m(7+6 m)]\right\}}{\left\{a f \sqrt{2 m(2+3 m)}\left[1+3 m\left(1+m+m^{2}\right)\right]+m^{2}\left[a^{2}(2+3 m)+2 f^{2}(1+2 m)\left(1+m+m^{2}\right)\right]\right\}^{2}}<0 .
\end{aligned}
$$

Lemma 1: The optimal degree of privatization is decreasing in the number of private retailers and the entry cost, while it is increasing in the market scale.

The reasons for Lemma 1 are that, firstly, when the competition of downstream market is intensive, the degree of privatization should decline in order to enhance the supply of intermediate goods. Secondly, when the entry cost is increasing and the competition of upstream market is moderate, the government should decline the optimal degree of privatization.

In addition, we find that the government's optimum policy is always partially privatization no matter in the situation with entry barrier in the short run or with free entry in the long run. The consideration of wholesale/retail structure in this paper may explain why the above result differs from that in Matsumura and Kanda [2]

Proposition 2: In an environment with mixed oligopoly in the wholesale market and many firms in the retail market, the public wholesaler should be partially privatized ${ }^{6}$ When $\lambda^{E}=0$, we get the private retailer number, $m^{E}\left(\lambda^{E}=0\right)=2 f^{2} /\left(a^{2}-4 f^{2}-a \sqrt{a^{2}-2 f^{2}}\right)<1$. If $m \geq 2,0<\lambda^{E}<1$ implies that the government's optimal privatization policy in the long run is partially privatization.

${ }^{7} \mathrm{~m} \geq 2$ implies that the retail market is by no means monopoly.

${ }^{8}$ Matsumura and Kanda [2] suggest that the government's optimum privatization policy in the long run be sole public ownership in the final goods market. 
when there is free entry in the wholesale market in the long run.

As argued in Matsumura and Kanda [2], marginal cost pricing of the public firm is the best in mixed oligopoly at the free entry market. In other words, the optimal degree of privatization is achieved when marginal cost of the public firm is equal to the equilibrium price. After characterizing the short-run and long-run optimal privatization policies respectively, to compare which one is larger than another, we compare by $\lambda^{E}-\lambda^{*}$, namely,

$\lambda^{E}-\lambda^{*}$

$=\frac{m\left\{a^{2} m(2+3 m)+\sqrt{2} a f \sqrt{m(2+3 m)}[m(m-2)-1]-2 f^{2} m^{2}(1+2 m)\right\}}{a^{2} m^{2}(2+3 m)+\sqrt{2} a f \sqrt{m(2+3 m)}\left[1+3 m\left(1+m+m^{2}\right)\right]+2 f^{2} m^{2}(1+2 m)\left(1+m+m^{2}\right)}$

$$
-\frac{m(1+m) n}{1+m(1+m)(4+n)}
$$

Proposition 3. The difference of optimal degree of privatization between long-run and short-run is increasing in the market scale and decreasing in the entry cost. The optimal degree of privatization in long-run is smaller than in short-run, when the market scale is restricted or the entry cost is high.

The reasoning is provided in Lemma 1.

From the comparison of Equation (16) and (28), we see that the entry of firm in the downstream market will increase the optimal degree of privatization in the short run but it may adjust the optimal degree of privatization in the long run. The reasoning is that in short run, as the market competition in the downstream market became intensive and that will make the market overproduced which lead the government to use the privatization policy in the wholesaler market as the instrument to reduce the supply of the public firm and hence, mitigate the adverse effect of overproduction in the retail market; but in the long run, since the profit of the firms in the wholesaler market is driven to zero and the number of the firm is restricted by the industry scale, the government should reduce the scale of optimal degree of privatization and increase the production of the semi-public firm to cope with the intensive competition in the retailers market.

\section{Concluding Remarks}

The major finding of this paper lies in the consideration of both the public wholesaler and the government's privatization policy in a vertical structure. We analyze the economic effect of the optimal privatization policy in the short run and in the long run, and have the following conclusions: Firstly, in an environment with mixed oligopoly in the wholesale market and many private firms in the retail market, the public wholesaler should be partially privatized in the short run. Besides, the more private firms are in wholesalers or retailers market, the higher degree of privatization the government should take. Secondly, the public wholesaler should be partially privatized in the long run; moreover, the more private retailers firms are in the market, the less degree of privatization the government should take. Thirdly, the difference of optimal degree of 
privatization between long run and short run is increasing in the market scale and decreasing in the entry cost. Hence, the optimal degree of privatization in long run is smaller than in short run, when the market scale is restricted and the entry cost is high.

\section{References}

[1] Matsumura, T. (1998) Partial Privatization in Mixed Duopoly. Journal of Public Economics, 70, 473-483. http://dx.doi.org/10.1016/S0047-2727(98)00051-6

[2] Matsumura, T. and Kanda, O. (2005) Mixed Oligopoly at Free Entry Markets. Journal of Economics, 84, 27-48. http://dx.doi.org/10.1007/s00712-004-0098-Z

[3] Brandão, A. and Castro, S. (2007) State-Owned Enterprises as Indirect Instruments of Entry Regulation. Journal of Economics, 92, 263-274. http://dx.doi.org/10.1007/s00712-007-0286-y

[4] Fujiwara, K. (2007) Partial Privatization in a Differentiated Mixed Oligopoly. Journal of Economics, 92, 51-65. http://dx.doi.org/10.1007/s00712-007-0267-1

[5] Wang, L.F.S. and Chen, T.L. (2010) Do Cost Efficiency Gap and Foreign Competitors Matter Concerning Optimal Privatization Policy at the Free Entry Market? Journal of Economics, 100, 33-49. http://dx.doi.org/10.1007/s00712-010-0117-4

[6] Jiang, L. (2006) Welfare Analysis of Privatization in a Mixed Market with Bargaining. Contemporary Economics Policy, 24, 395-406. http://dx.doi.org/10.1093/cep/byj029

[7] Bárcena-Ruiz, J.C. and Garzón, M.B. (2003) Mixed Duopoly, Merger and Multiproduct Firms. Journal of Economics, 80, 27-42. http://dx.doi.org/10.1007/s00712-002-0605-2

[8] Méndez-Naya, J. (2008) Merger Profitability in Mixed Oligopoly. Journal of Economics, 94, 167-176. http://dx.doi.org/10.1007/s00712-008-0001-7

[9] Heywood, J. and Ye, G. (2008) Delegation in a Mixed Oligopoly: The Case of Multiple Private Firms. Managerial and Decision Economics, 30, 71-82. http://dx.doi.org/10.1002/mde.1436

[10] De Fraja, G. and Delbono, F. (1989) Alternative Strategies of a Public Enterprise in Oligopoly. Oxford Economic Papers, 41, 302-311.

Submit or recommend next manuscript to SCIRP and we will provide best service for you:

Accepting pre-submission inquiries through Email, Facebook, LinkedIn, Twitter, etc.

A wide selection of journals (inclusive of 9 subjects, more than 200 journals)

Providing 24-hour high-quality service

User-friendly online submission system

Fair and swift peer-review system

Efficient typesetting and proofreading procedure

Display of the result of downloads and visits, as well as the number of cited articles

Maximum dissemination of your research work

Submit your manuscript at: http://papersubmission.scirp.org/

Or contact me@scirp.org 